\title{
EKSTRAKSI PIGMEN KAROTENOID PADA CANGKANG KEPITING SEBAGAI PEWARNA ALAMI YANG SEHAT
}

\author{
Nasriani \\ Program Studi Budidaya Perairan Fakultas IImu-ilmu Pertanian \\ Univesitas Muhammadiyah Gorontalo \\ Email: nasriani.90@yahoo.com
}

\begin{abstract}
Extraction of carotenoid pigments from crab shells is a step to create healthy natural dyes through the utilization of industrial waste. Because, crab shells contain various types of carotenoid pigments that serve as provitamin $A$ and antioxidants for the body. This research used maseration method by using silent solvent at room temperature. In the extraction process used 2: 1 solvent ratio with the shell then stored in a freezer temperature -20oC then applied to sausage and onde-onde food products. The resulting carotenoid pigment was analyzed using a spectrophotometer. The results showed that in $1 \mathrm{~kg}$ of shell produced $531.25 \mathrm{~mL} / \mathrm{kg}$ dye of carotenoid pigment consisting of pigment type astaxanthin, lutein, lycopene, $\beta$-carotene and cantaxanthin which served as provitamin $A$ and antioxidant. Therefore the natural dye of the potent crab shells is used as a healthy natural dye.
\end{abstract}

Keywords: food coloring, carotenoids, crab shells

\section{Abstrak}

Ekstraksi pigmen karotenoid dari cangkang kepiting merupakan suatu langkah untuk menciptkan pewarna alami yang sehat melalui pemanfaatan limbah hasil industri. Sebab, cangkang kepiting mengandung berbagai jenis pigmen karotenoid yang berfungsi sebagai provitamin A dan antioksidan bagi tubuh.Penelitian ini menggunakan metode maserasi dengan menggunakan pelarut diam pada suhu ruangan. Dalam proses ekstraksi digunakan perbandingan pelarut $2: 1$ dengan cangkang kemudian disimpan dalam freezer bersuhu $-20^{\circ} \mathrm{C}$ kemudian diaplikasikan pada produk makanan sosis dan onde-onde. Pigmen karotenoid yang dihasilkan dianalisa dengan menggunakan spektrofatometer. Hasil menunjukkan bahwa dalam $1 \mathrm{~kg}$ cangkang dihasilkan $531,25 \mathrm{~mL} / \mathrm{Kg}$ pewarna dari pigmen karotenoid yang terdiri dari jenis pigmen astaxanthin, lutein, likopen, $\beta$-caroten dan cantaxanthin yang berfungsi sebagai provitamin A dan antioksidan. Oleh karena itu pewarna alami dari cangkang kepiting potensil digunakan sebagai pewarna alami yang sehat.

Kata kunci: pewarna makanan, karotenoid, cangkang kepiting 


\section{PENDAHULUAN}

Makanan adalah hal yang tidak dapat dipisahkan dari kehidupan manusia. Makanan yang baik adalah makanan yang sehat dan aman untuk dikonsumsi. Hal ini disebabkan karena makanan yang tidak sehat dan tidak aman akan mengganggu kesehatan hingga menimbulkan kematian. Oleh karena itu, industry pangan harus memenuhi standar mutu dan keamanan pangan yang ditetapkan pemerintah.

Pada era modern saat ini, bahan pewarna makanan adalah hal yang tidak bias dipisahkan dari berbagai jenis makanan dan minuman olahan. Produsen pun berlomba-lomba untuk menarik perhatian para konsumen dengan menambahkan pewarna pada makanan dan minuman (Surdijati, 2010). Zat pewarna yang digunakan padamakanan adalah senyawa berwarna yang mempunyai afinitas kimia terhadap benda yang diwarnainya. Warna padaproduk makanan ataupun minuman adalah factor penting yang bias menjadi daya tarik konsumen. Warna adalah factor dasar dalam menentukan kualitas suatu makanan (Cahyadi, 2009).

Bahan pewarna yang sering digunakan dalam makanan olahan terdiri dari jenis pewarna sintetis (buatan) dan pewarna natural (alami). Pewarna sintetis berasal dari bahan kimia, seperti tartrazin untuk warna kuning atau Alleura red untuk warna merah. Demi mendapatkan

keuntungan,

produsen sering menggunakan pewarna tekstil pada makanan. Ada yang menggunakan Rhodamin $B$ pewarna tekstil untuk mewarnai terasi, kerupuk dan minuman sirup. Padahal penggunaan pewarna jenis tersebut dilarang digunakan karena dapat memicu kanker dan penyakit lainnya. Pewarna sintetis yang boleh digunakan untuk makananpun harus dibatasi penggunaannya, karena pada dasarnya, setiap senyawa sintetis yang masuk ke dalam tubuh akan menimbulkan efek (Sarmalin, 2010).

Menurut Tresnati (2003) salah satu pewarna yang ditemukan dalam pangan adalah pewarna sintetis Rhodamin B yang seharusnya hanya digunakan untuk pewarna tekstil. Walaupun memiliki toksisitas yang rendah, tetapi penggunaan dalam jumlah besar maupun berulang-ulang menyebabkan sifat kumulatif dalam tubuh seperti iritasi saluran pernafasan, iritasi kulit, iritasi pada mata,iritasi pada saluran pencernaan, keracunan dan gangguan hati. Oleh karena penggunaan pewarna sintetis perlu diminimalisir dan diganti dengan pewarna alami yang lebih aman. Pewarna alami dapat diperoleh dari tumbuhan ataupun cangkang hewan. Berdasarkan hal tersebut, dipandang penting untuk melakukan penelitian terkait ekstraksi pewarna alami dari cangkang kepiting. Hal ini 
diharapkan bisa menjadi solusi untuk menghindari penggunaan pewarna berbahaya pada pangan.

\section{METODE PENELITIAN}

Penelitian ini dilakukan di Kota Makassar, Sulawesi Selatan. Ekstraksi dan pengujian sampel dilakukan di Laboratorium Teknologi Hasil Perikanan Jurusan Perikanan, Fakultas Perikanan dan IImu Kelautan Universitas Hasanuddin Makassar. Jenis desain penelitian yang digunakan adalah penelitian eksperimen. Proses penelitian terbagi atas dua bagian yaitu persiapan sampel, ekstraksi pigmen karotenoid dan aplikasi pigmen karotenoid pada makanan. Pigmen karotenoid yang dihasilkan dianalisa dengan menggunakan spektrofatometer.

\section{Persiapan Sampel}

Sampel yang digunakan adalah cangkang kepiting rajungan. Sebelum diekstraksi, cangkang kepiting tersebut dibersihkan dan dikeringkan kemudian dihaluskan. Proses penghalusan cangkang kepiting dilakukan dengan menggunakan lumping.

\section{Ekstraksi Pigmen Karotenoid}

Ekstraksi pigmen karatenoid pada cangkang kepiting menggunakan jenis ekstraksi maserasi. Prosedur kerja dari ekstraksi pigmen karatenoid pada cangkang kepiting dengan metode maserasi adalah sebagai berikut.

a. Timbang cangkang kepiting. b. Masukkan ke dalam gelas ukur volume 2 liter.

c. Tambahkan aseton dengan perbandingan 2 : 1 dengan cangkang dan aduk selama 5 menit kemudian saring menggunakan kertas saring nomor 1.

d. Bilas ampas hasil saringan dengan aseton.

e. Saring hasil ekstraksi kemudian uapkan pada kondisi vakum pada suhu $40^{\circ} \mathrm{C}$ dengan menggunakan rotary evaporator.

f. Recover pigmen menggunakan minyak goreng sebanyak $5 \mathrm{ml}$.

g. Pindahkan minyak yang mengandung pigmen ke dalam botol gelap (botol sampel).

h. Simpan di dalam freezer pada suhu $-20^{\circ} \mathrm{C}$.

Aplikasi Pigmen Karotenoid pada Makanan

$$
\text { Pewarna alami yang }
$$
dihasilkan akan diaplikasikan pada produk makanan berupa sosis, dan onde-onde. Pewarna alami tersebut akan dicampurkan kedalam makanan hingga homogen.

\section{HASIL DAN PEMBAHASAN}

Persiapan bahan baku

Bahan baku berupa cangkang kepiting yang diperoleh dari Industri Perikanan dibersihkan terlebih dahulu dari sisa daging yang masih melekat dengan cara disikat dengan menggunakan sikat gigi (Gambar 1a). Setelah disikat, cangkang kemudian dibilas dengan air bersih kemudian dikeringkan. 
Proses pegeringan cangkang tidak boleh dilakukan diruang terbuka atau dibawah terik matahari. Hal ini disebabkan karena karotenoid sangat terhadap cahaya dan suhu yang terlalu tinggi (Kurniadi, 2010). Oleh karena itu, digunakan oven dengan suhu $50^{\circ} \mathrm{C}$ untuk mengeringkan cangkang (Gambar 1b).
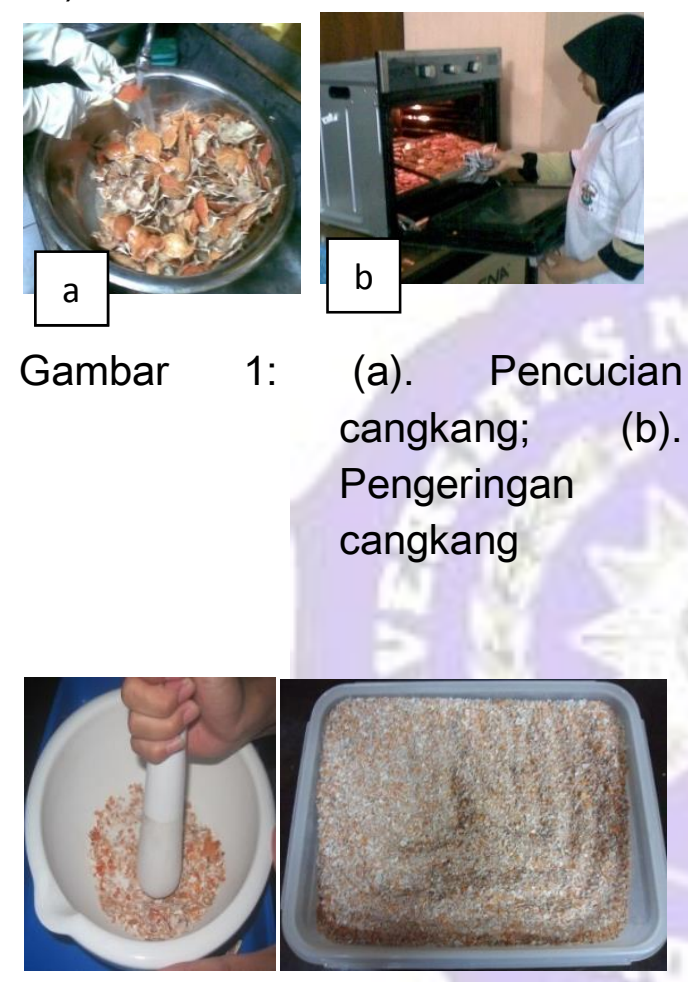

Gambar 2. Penghalusan cangkang

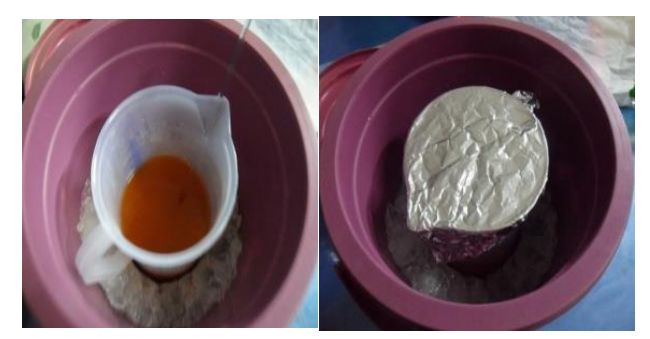

Gambar 3. $\begin{gathered}\text { Ekstraksi pigmen } \\ \text { karotenoid }\end{gathered}$

Ekstraksi dilakukan pada ember yang berwarna gelap dan
Proses pengeringan dimaksudkan untuk mengurangi kadar air dalam cangkang. Setelah kering, cangkang kemudian dihaluskan dengan menggunakan lumping porselen hingga menjadi bubuk halus (Gambar 2).

Ekstraksi pigmen karotenoid pada cangkang kepiting

Ekstraksi pigmen karotenoid yang digunakan adalah ekstraksi maserasi dengan menggunakan larutan aseton (Gambar 3). Menurut Mukhriani (2014) metode maserasi memiliki beberapa kelebihan seperti cara pengerjaan dan unit alat yang digunakan sederhana, biaya operasional relative rendah, serta dapat menghindari rusaknya senyawasenyawa yang bersifat termolabil.diberi es curah. Penggunaan ember berwarna gelap dan es curah dimaksudkan untuk menghindari terjadinya kontaminasi dari cahaya dan suhu lingkungan. Pada proses ini dihasilkan pigmen karotenoid seperti telihat pada Gambar 4.

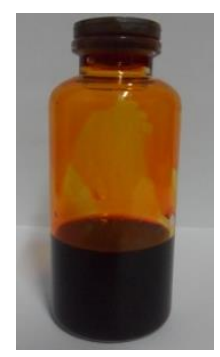

Gambar 4. Pigmen Karotenoid 
Pigmen karotenoid menurut Briton et al., (2008) dalam Makalalag et al., (2017) adalah precursor vitamin $A$ yang dimetabolisme dari $\beta$-karoten. $\mathrm{Di}$ dalam tubuh manusisa, precursor vitamin A akan menjadi vitamin A setelah melalui proses metabolism. Menurut Landrum (2010), Vitamin A berguna bagi aktivitas fisiologis tubuh khususnya mata, melindungi jaringan permukaan kulit dari pengaruh paparan sinar matahari yang tinggi, antioksidan dan antikanker.

Pigmen karotenoid yang dihasilkan dianalisa dengan spektrofatometer. Hasil analisa pigmen karotenoid dapat dilihat pada Gambar 5.

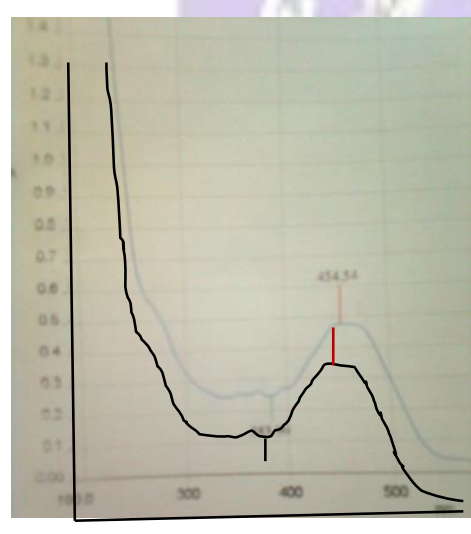

Gambar 5. Hasil analisa pigmen karotenoid

Berdasarkan Gambar 5 dapat diketahui bahwa jenis pigmen karotenoid yang terdapat pada cangkang kepiting didominasi oleh pigmen astaxanthin. Menurut Nurdianti et al., (2017), astaxanthin adalah kelompok karotenoid xantofil yang larut dalam lemak dan banyak ditemukan pada berbagai organism dan hewan laut. Selain itu juga pada cangkang kepiting yang diekstraksi ditemukan lutein, likopen, $\quad \beta$-karoten dan cantaxanthin. Lutein adalah suatu karotenoid non provitamin A, yang menurut Tanjung dan Damayanti (2013) dapat melindungi mata terhadap degenerasi macula yang berhubungan dengan usia (agerelated macular degeneration, ARMD) serta katarak. Sementara likopen menurut Mu'nisa (2012) sering pula disebut sebagai $\alpha$ caroten yaitu suatu karotenoid pigmen merah terang yang memiliki kemampuan untuk mengendalikan radikal bebas 100 kali lebih efisien daripada vitamin E atau 12500 kali dari gluthation. Likopen berfungsi sebagai anti skin aging serta mampu mencegah penyakit cardiovascular, kencing manis, osteoporosis, infertilitas, dan kanker terutama kanker prostat.

Beta-karoten

( $\beta$-karoten) adalah antioksidan yang memilingi fungsi untuk melindungi tubuh dari radikal bebas yang dapat menyebabkan kerusakan pada sel melalui proses oksidasi. Paparan radikal bebas dalam waktu yang lama dapat memicu sejumlah penyakit kronis seperti penyakit jantung dan kanker (Ehrlich, 2010). Oleh karena itu, menurut Champe at al., (2005), mengkonsumsi makanan yang kaya kana betakaroten bias menurunkan resiko penyakit jantung dan kanker. Konsumsi makanan yang kaya 
akan beta-karoten juga akan menurunkan resiko terkena penyakit katarak dan degenerasi macula.

\section{Aplikasi Pada Produk Makanan}

Karotenoid yang dihasilkan diaplikasikan pada produk makanan berupa sosis ikan dan onde-onde. Dari hasil aplikasi tersebut dapat diketahui bahwa sosis dan onde-onde yang dihasilkan memiliki warna yang lebih menarik (Gambar 6). Meskipun menggunakan pewarna, produk tersebut tetap aman dan sehat untuk dikonsumsi. Hal tersebut disebabkan karena pewarna yang digunakan adalah pewarna alami yang sehat dan memiliki kandungan sebagai provitamin A dan sebagai antioksidan.
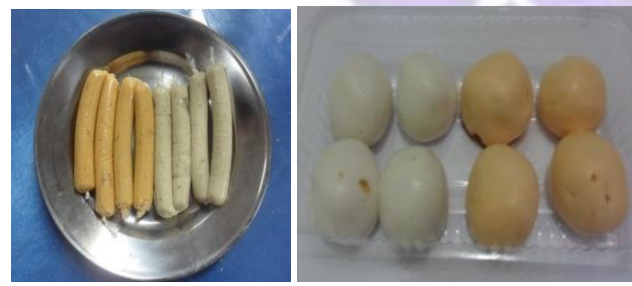

Gambar 6. Sosis dan onde-onde yang menggunakan pigmen karotenoid (berwarna orange)

\section{KESIMPULAN}

Cangkang kepiting potensial dijadikan sebagai sumber karotenoid yang sangat penting untuk menunjang kesehatan manusia. Pewarna alami dari cangkang kepiting potensial digunakan sebagai pewarna alami.

\section{DAFTAR PUSTAKA}

Kurniady, Y, E. 2010. Bab_/V_pp_1-33.

eprints.undip.ac.id/22781/1/B ab_I-V_pp_1-33.pdf. Diakses pada tanggal 1 Februari 2018

Landrum, J. T. 2010. CarotenoidsPhysical, Chemical, and Biological Function and Properties. CRC Press. New York.

Makalalag, S, Darus S.J.P., dan Desy M.H.M.2017.

Penentuan Kandungan Pigmen Karotenoid Pada Kepiting Grapsus albolineatus (Lamarck) Betina Dari Perairan Pesisir PAntai Desa Tanawangko. Jurnal Pesisir dan Laut Tropis. Volume 3 Nomor 1 Tahun 2017.

Mu'nisa, A. 2012. Analisis Kadar Likopen dan Uji Aktivitas Antioksidan pada Tomat Asal Sulawesi Selatan. Jurnal Bionature, Volume 13, Nomor 1, Tahun 2012.

Mukhriani, Y. 2014. Ekstraksi, pemisahan senyawa identifikasi senyawa aktif. Jurnal Kesehatan. Volume 7 Nomor 2 Tahun 2014.

Nurdianti L., Ratih A., dan Indra I. 2017. Formulasi dan Karakterisasi SNE (Self 
Nanoemulsion) Astaxanthin dari Haematococcus pluvialis sebagai Super Antioksidan Alami. Jurnal Sains Farmasi \& Klinis. Volume 4, Nomor 7 Tahun 2017.

Sarmalin, O. 2010. Identifikasi pewarna sintetik pada produk pangan yang beredar di Jakarta dan Ciputat. Artikel. Karya Tulis IImiah. Jakarta. Universitas Indonesia

Surdijati, Anyar S., Lanni W. 2010. Identifikasi dan penetapan kadar zat warna merah dalam dawet secara $K L T$ - densitometri. Yogyakarta: Kanisius.

Tanjung, C,. Damayanti, R.S. 2013. Manfaat Penambahan Lutein dalam Susu Formula: Tinjauan Sistematik. Jurnal CDK-200, Volume 40 Nomor 1, Tahun 2013.

Trestiati, M. 2003. Analisis Rhodamin B pada Makanan dan Minuman Jajanan Anak SD (Studi Kasus: Sekolah Dasar di Kecamatan Margaasih Kabupaten Bandung). Thesis. ITB. Bandung. 